\title{
Cryptococcal meningitis in Hong Kong
}

\author{
C. T. HUANG, P. C. WONG, AND C. H. CHAN-TEOH \\ From the Department of Pathology and Bacteriology, University of Hong Kong
}

SYNOPSIS The clinical and bacteriological findings in three cases of cryptococcal meningitis which occurred in Hong Kong are reported. The bacteriological investigations are discussed.

Littman and Zimmerman (1956) reported that there were over 300 cases of human cryptococcosis on record, yet compared with other systemic mycoses human cryptococcosis is still a rare clinical entity. Of all cases of human cryptococcosis reported, cryptococcal meningitis or meningoencephalitis is the most frequently encountered. The nervous symptoms and the ease with which the causal organism can be isolated from the cerebrospinal fluid enable prompt diagnosis. As far as we are aware there have been eight cases of cryptococcosis reported in China, and the scattered reports have been comprehensively reviewed by Cheng (1956). Three more cases in which the patients were also Chinese appeared in Malaya and Singapore (Pallis, 1949; Loh, 1951 ; Russell and Dean, 1957). Nevertheless, with a large population and only a dozen or so cases reported, it indicates that cryptococcosis amongst the Chinese race must be rare. In contrast to this belief, we have encountered three cases of cryptococcal meningitis in Hong Kong between December 1958 and December 1961. All the patients were Chinese and all died. The clinical records and the bacteriological investigations of these three cases are presented here to show that the incidence of cryptococcosis is probably higher than that found in the medical literature.

\section{CASE REPORTS}

CASE 1 A man aged 30 years, occupation unknown, was admitted to a private hospital in November 1958 complaining of frontal headache, diplopia, insomnia, and rapid loss of weight. Stained smears of cerebrospinal fluid examined at that stage showed acid-fast bacilli. He was treated for tuberculosis with streptomycin, P.A.S. and I.N.A.H. for 14 days but there was no significant improvement and the patient then developed signs of cerebellar dysfunctioning. He was transferred to the Queen Mary Hospital on 5 December 1958 for further investigation.

Received for publication 14 January 1963
On admission, he was found to be mentally confused and drowsy. His temperature was $100^{\circ} \mathrm{F}$., blood pressure $A$ $160 / 100 \mathrm{~mm}$. $\mathrm{Hg}$, and pulse rate 64 per minute. Left 윽 facial palsy, nystagmus, and bilateral papilloedema were $\vec{\sim}$ noted. Ventriculography showed evidence of incomplete $\mathcal{A}$ posterior fossa block. Tuberculous meningitis with $\frac{D}{\square}$ basal adhesion was suspected, but smears of cerebro- $\frac{\mathbb{D}}{3}$ spinal fluid showed numerous yeast-like cells, which $\bar{\partial}$ were subsequently identified as Cryptococcus neoformans $\stackrel{\mathbb{D}}{-}$ by culture. At operation basal arachnoiditis with adhesion $\vec{\varphi}$ was observed and the adhesion was separated to establish of free passage of cerebrospinal fluid. A portion of the meninges removed for histological examination showed cryptococcosis. Tubercle bacilli were not found by smears, culture, or guinea-pig inoculation. The patient died eight days after admission. Permission for necropsy was refused.

CASE 2 A man aged 31 years, single and a tailor by $\overrightarrow{\overrightarrow{0}}$ profession, came to Hong Kong from Shanghai 10 years ago and was well until two weeks before admission when he began to experience attacks of vertigo and severe, persistent headache over the occipital and temporal regions. He had had no fever since the onset of the illness. $?$ His parents and 11 brothers and sisters were living with him but none of them had the same complaint.

The patient was admitted to the Nethersole Hospital on 18 January 1960 . On admission, he was mentally clear, had no neck rigidity, and Kernig's sign was negative. The fundi showed bilateral papilloedema with many small haemorrhagic spots. There were no palpable lymph $D$ glands. Blood pressure was $130 / 90 \mathrm{~mm}$. $\mathrm{Hg}$ and the pulse rate was 80 per minute.

Haemoglobin was 14 g./100 ml.; W.B.C.s 6,700/c. mm. (74\% neutrophils and $26 \%$ lymphocytes); E.S.R. $N$ $4 \mathrm{~mm}$./hr.; the Kahn test was negative.

Cerebrospinal fluid was at a pressure of $250 \mathrm{~mm}$. The Queckenstedt test showed a quick rise and slow fall and Pandy's test was negative. Concentrations of sugar were $10 \mathrm{mg} . / 100 \mathrm{ml}$. and of chloride $460 \mathrm{mg} . / 100 \mathrm{ml}$. No cobweb formation or acid-fast bacilli were seen.

On the second day after admission and on four occasions subsequently $C$. neoformans was found in the cerebrospinal fluid either in smears or by culture.

Radiographs of the chest showed tuberculous infilt- $\mathbb{D}$ ration in the right middle zone; the skull was normal. 
The patient also had an ulcer on the left forearm. To rule out primary foci, the sputum and the scab from the ulcer were examined for $C$. neoformans, which was not, however, found. Mycobacterium tuberculosis was not found in sputum when examined by smears, culture, and guinea-pig inoculation.

The patient was treated with nystatin (500,000 units) and sulphadiazine (1 g.) given by mouth every four hours. Subjectively he felt better, but his condition suddenly deteriorated on the tenth day after admission and he died six days later.

CASE 3 A man, aged 31, an enamel worker, had been in good health until three years ago when he began to have recurrent episodes of vertigo, which was not related to posture, but without tinnitus or impairment of hearing. The vertigo had apparently been less frequent in the past eight months although no treatment or investigation was carried out during this time. Three weeks before admission the patient had an acute attack of bilateral and vertical headache, which was very persistent and dull and aching in character. He also complained of diplopia, especially on looking towards the left side. He was admitted to the Queen Mary Hospital on 6 December 1961.

On examination, there was paralysis of the left lateral rectus. Since the patient had been an enamel worker for 30 years, chemical investigation of blood and radiographical studies of the epiphyses for lead absorption were done with negative results. Radiographs of the chest and tests of the blood and cerebrospinal fluid for venereal disease were all negative. Pandy's test was positive: total protein $30 \mathrm{mg} . / 100 \mathrm{ml}$; sugar $40 \mathrm{mg} . / 100 \mathrm{ml}$; chloride 680 $\mathrm{mg} . / 100 \mathrm{ml}$. Bacteriological examination of the cerebrospinal fluids taken on the fifth, seventh and 14th days after admission showed $C$. neoformans in smears and by cultural methods on each occasion. The first cerebrospinal fluid specimen was also examined for tubercle bacilli by smears, culture, and guinea-pig inoculation, but with negative results.

The patient was treated with amphotericin B, $1 \mathrm{mg}$. per kg. daily, given intravenously. In spite of the treatment, which had been given for 10 days, he died on 3 January 1962. Escherichia coli was isolated from blood three days before death but $C$. neoformans was not found, showing that the fungus had not been disseminated into the blood stream. Permission for necropsy was not available.

\section{BACTERIOLOGY}

The cerebrospinal fluids of the three cases were examined in the same manner. The sediments of the centrifuged fluids were first examined by direct smears mounted in Indian ink and in lactophenol cotton blue and afterwards in smears stained by Gram's method. They were then cultured on Sabouraud's glucose agar incubated in duplicate at $37^{\circ} \mathrm{C}$. and at room temperature. Cultures on fresh and heated human blood agar media incubated at $37^{\circ} \mathrm{C}$. were also made in order to detect other pathogenic bacteria. After isolation, subcultures in appropriate media were incubated at $37^{\circ} \mathrm{C}$. to be examined for mycelium formation, for sugar fermentation reactions, for nitrogen and carbon assimilations, for urea hydrolysis, for indole production, and for nitrate reduction. Finally, tests for animal pathogenicity were carried out by inoculating the isolates into white mice and guinea-pigs. The results of these tests are summarized in Table $I$.

Thickly encapsulated, budding, yeast-like cells were seen in direct smears of the sediments of the centrifuged cerebrospinal fluids. The yeast-like cells were round, rarely oval, and varied a great deal in diameter. Excluding the capsule, the diameter varied from 3 to $25 \mu$ but the majority were about $10 \mu$ in diameter. The cells were Gram positive. The capsules could be seen clearly in wet smears mounted in lactophenol cotton blue examined under subdued light (Fig. 1) but were also conveniently demonstrated by India-ink preparations (Fig. 2).

The growth was very profuse on Sabouraud's glucose medium incubated at $37^{\circ} \mathrm{C}$. Well-developed colonies about 2 to $5 \mathrm{~mm}$. in diameter, which were heaped up, dome-shaped, creamy white and mucoid (Fig. 3), formed within 48 hours. Smears from these cultures showed encapsulated budding yeast-like cells not unlike those seen in direct smears, except that the capsules were narrower and not so well defined and that the cells were more regular in size. Upon further incubation, the colonies changed from

TABLE I

RESULTS OF BIOCHEMICAL AND PATHOGENICITY TESTS OF THREE STRAINS OF C. NEOFORMANS

$\begin{array}{llccccc}\text { Strain } & \begin{array}{l}\text { Growth } \\ \text { at } 37^{\circ} \text { C. }\end{array} & \begin{array}{l}\text { Indole } \\ \text { Production }\end{array} & \begin{array}{l}\text { Reduction } \\ \text { of Nitrate } \\ \text { to Nitrite }\end{array} & \begin{array}{l}\text { Urea } \\ \text { Hydrolysis }\end{array} & \begin{array}{l}\text { KNOs } \\ \text { Assimilation }\end{array} & \begin{array}{l}\text { Carbon Assimilation from } \\ \text { for Mice }\end{array} \\ & & & & & & \end{array}$




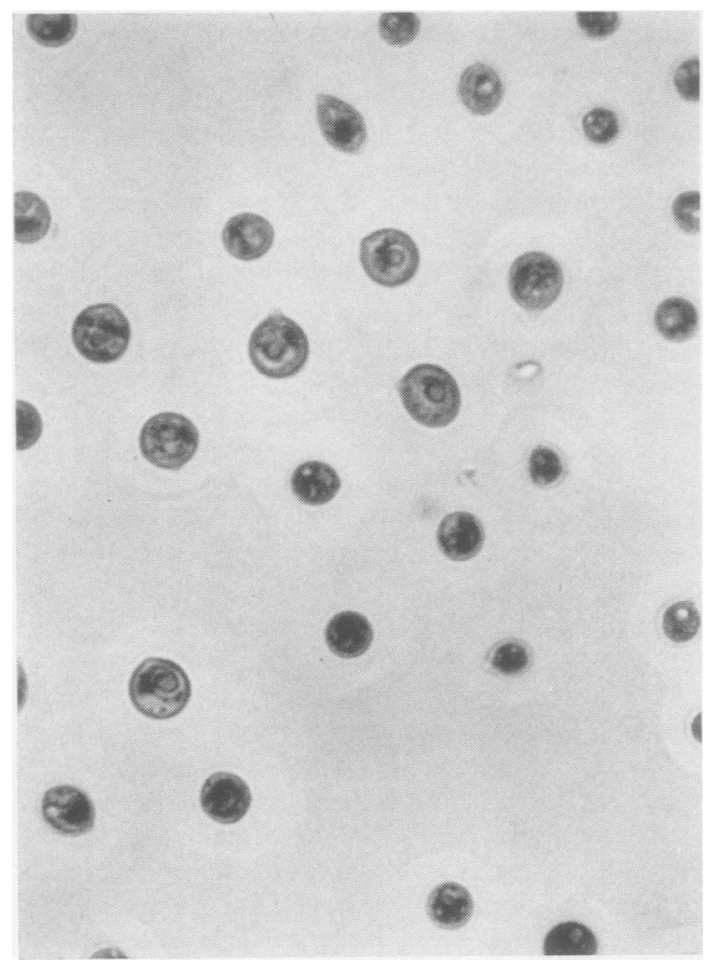

FIG. 1. C. neoformans from cerebrospinal fluid of case 2 mounted in lacto-phenol cotton blue. Capsules are clearly distinguishable. $\times 600$.

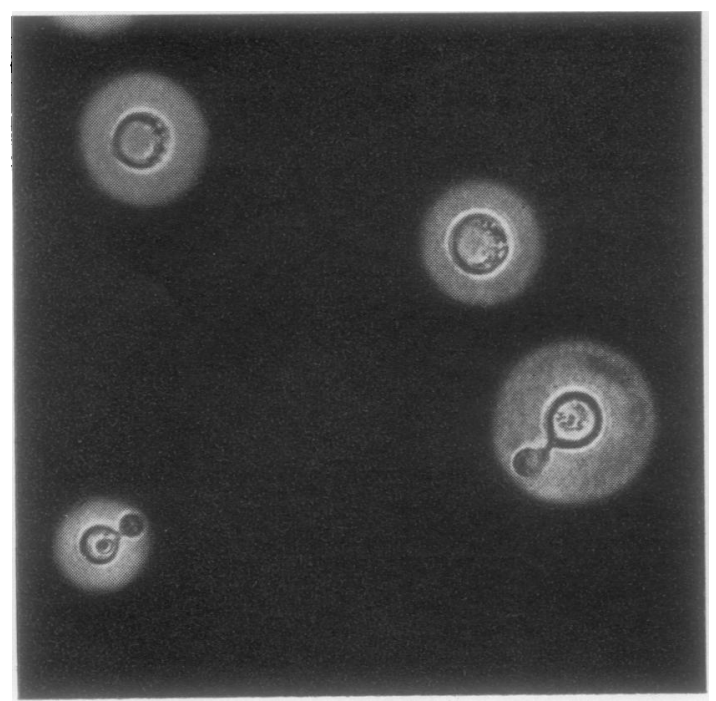

FIG. 2. C. neoformans from cerebrospinal fluid of case 2 in Indian-ink preparation. $\times 275$. creamy white to brown and were drier. Mycelium $\frac{\mathrm{O}}{\mathrm{V}}$ was not formed even after prolonged incubation $\overrightarrow{\vec{F}}$ both at $37^{\circ} \mathrm{C}$. and at room temperature, nor was it $\stackrel{\circ}{+}$ formed in corn meal-agar subcultures. Though the growth was slower at room temperature between $\frac{\overline{\bar{O}}}{\bar{D}}$ 25 and $28^{\circ} \mathrm{C}$. it was just as good as at $37^{\circ} \mathrm{C}$. upon $\vec{\sigma}$ further incubation. Subsequent tests in broth cul- $\_$ tures with an initial $p \mathrm{H}$ of 7.4 showed that the $p \mathrm{H}$ of $\nRightarrow$ the medium increased with time, reaching 8.0-8.3 $\vec{\circ}$ after one week's incubation at $37^{\circ} \mathrm{C}$. for cultures of $\stackrel{-}{-}$ all three strains.

Growth on fresh and heated blood agar media yielded poor growth. Only minute pinpoint colonies? measuring less than $1 \mathrm{~mm}$. in diameter developed in $\vec{\sigma}$ two or three days' time. The colonies were not ir appreciably bigger even after many days of incuba- $\vec{D}$ tion. No haemolysis was noticed from growth in +

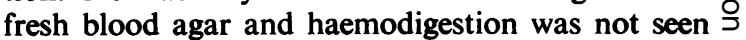
in heated blood agar medium.

Biochemically, none of the three strains produced $\mathscr{D}$ indole from peptone broth, or reduced nitrate to nitrite. They produced acid but no gas in fluid 3 medium containing glucose and mannose in two days. $\frac{\mathbb{\Phi}}{-}$ No change was observed in maltose, mannite, $\vec{\oplus}$ sucrose, salicin, lactose, and galactose after 14 days' incubation at $37^{\circ} \mathrm{C}$. For carbon assimilation and nitrogen assimilation tests, the methods of Lodder and Kreger van Rij (1952) were followed. In the latter potassium nitrate (Analar) was used. A negative control was always included by inoculating the cultures onto each batch of the basal medium. The $\stackrel{\mathbb{\Omega}}{\Omega}$

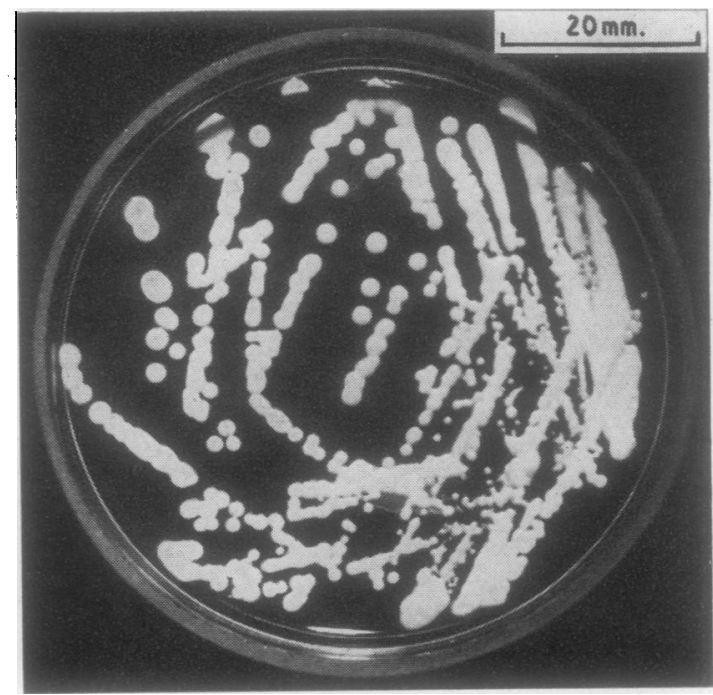

FIG. 3. Culture of C. neoformans from case 2 in Sabouraud's glucose agar incubated at $37^{\circ} \mathrm{C}$. for 48 hours. 
results showed that carbon was assimilated from glucose, mannose, maltose, mannite, sucrose, and galactose but not from lactose and salicin. Nitrogen was not assimilated from potassium nitrate by any of the three strains. All strains hydrolysed urea within 24 hours of incubation. The results of all the bichemical tests are set out in Table I.

Sensitivity tests in vitro against antifungal agents such as actidione, nystatin (Mycostatin), and amphotericin B (Fungizone) were carried out. Because amphotericin B was not available when strains $\mathrm{I}$ and II were isolated, their stock cultures were used for testing. The antifungal agents were incorporated in melted Sabouraud's glucose agar $\left(p \mathrm{H} \mathrm{7.0)}\right.$ at $45^{\circ} \mathrm{C}$., poured on plates, and hardened immediately in the refrigerator. The concentrations of each agent used were: actidione $24,2.4$, and 0.24 $\mu \mathrm{g} . / \mathrm{ml}$.; nystatin 100,10 , and $1 \mathrm{unit} / \mathrm{ml}$; amphotericin B $10,1.0 \mu \mathrm{g} . / \mathrm{ml}$. The inoculum was one loopful of a 24-hour culture of the test strain in glucose broth $(p \mathrm{H} \mathrm{7.0)}$ streaked all over the surface of the plate. Glucose agar plates without antibiotics were seeded for control. All plates were incubated at $37^{\circ} \mathrm{C}$. for two days, and results were read with the aid of a dissection microscope. The results are presented in Table II. All the three strains were inhibited by amphotericin B within the range of inhibition in vitro studied elsewhere. Strains I and II were more resistant to actidione than strain III and all three were unusually resistant to nystatin. According to the information provided by the manufacturer the activity of nystatin decreases when a suspension is stored at $37^{\circ} \mathrm{C}$. The incubation temperature in our test definitely affected the result. On the whole, strain III differed from the other two strains in response to these antifungal agents. It was more sensitive to actidione but was more resistant to nystatin and amphotericin $B$ than the other two strains.

Benham (1956) has pointed out that the degree of invasiveness for mice is an important diagnostic characteristic for species of Cryptococcus and that only $C$. neoformans is pathogenic. All our strains were inoculated into white mice soon after isolation. For each isolate eight mice were inoculated, four receiving intraperitoneal and the other four intracerebral injections. Thesize of the inoculum per mouse for intraperitoneal injection was $0.5 \mathrm{ml}$. of a 24-hour glucose broth culture and that for intracerebral injection $0 \cdot 1 \mathrm{ml}$. of the same culture. The progress of the infection among the animals was very irregular, but on the whole those injected intraperitoneally died within two weeks of inoculation and those injected intracerebrally within 10 days. Necropsy findings in the mice were essentially the same for all three strains. The lungs were consolidated but the extent differed in each individual mouse. The brains were soft and congested or normal in appearance. A few of the animals showed a slightly enlarged spleen. The livers and kidneys were apparently normal in gross appearance. Those injected intraperitoneally often showed congested vessels of the abdominal wall and increase of peritoneal fluid, which was gelatinous. Histological study of sections of the organs, including the brains, showed numerous cryptococcal cells in the tissue spaces and the lumen of the vessels but the cellular reactions were mild in contrast to the overwhelming number of organisms present.

One locally bred and one Dunklin-Hartley strain of guinea-pig, weighing about 350 to $400 \mathrm{~g}$., were inoculated with each of the strains of $C$. neoformans isolated. One millilitre of a 24-hour glucose broth culture was injected subcutaneously into the left groin of each animal. The Dunklin-Hartley guineapigs died within one month of inoculation, varying from 25 to 30 days for strains I, II, and III respectively, whereas the locally bred animals showed an inconsistent result. That inoculated with strain I died 40 days after inoculation, whilst those inoculated with strains II and III survived for more than two months. Post-mortem examination of the DunklinHartley guinea-pigs thus infected showed large numbers of cryptococcal cells in the lungs and spleens microscopically, less so in the kidneys. There was little tissue reaction in the form of proliferation of the reticulo-endothelial cells and the brains and livers showed no change. Though the number of guinea-pigs used for our test was small, it is clear that variation between strains in susceptibility of guineapigs to infection is an important factor.

From the above findings the diagnosis of Cryptococcus neoformans of the three strains is justified, for all of them fulfilled the criteria laid down by Littman

TABLE II

END-POINT OF INHIBITION IN VITRO OF C. NEOFORMANS TO ANTIFUNGAL AGENTS

\begin{tabular}{|c|c|c|c|}
\hline & Actidione ( $\mu \mathrm{g} . / \mathrm{ml})$. & Nystatin (units/ml.) & Amphotericin B ( $\mu \mathrm{g} . / \mathrm{ml})$. \\
\hline $\begin{array}{l}\text { Strain I } \\
\text { Strain II } \\
\text { Strain III } \\
\text { End-point according to reference }\end{array}$ & $\begin{array}{l}2 \cdot 4 \\
2 \cdot 4 \\
0 \cdot 24 \\
0 \cdot 24 \text { (Littman and Zimmerman, } \\
1956)\end{array}$ & $\begin{array}{l}10 \\
10 \\
100 \\
1 \cdot 5 \text { (E. R. Squibb \& Sons, } \\
\text { technical leaflet, 1961) }\end{array}$ & $\begin{array}{l}0.1 \\
0.1 \\
1 \cdot 0 \\
0.03 \text { to } 0.6 \text { (Seabury and Dascomb, } \\
1960 \text { ) }\end{array}$ \\
\hline
\end{tabular}

Amphotericin B ( $\mu \mathrm{g} . / \mathrm{ml}$.)

0.03 to 0.6 (Seabury and Dascomb, 
and Zimmerman (1956). We had no opportunity to examine serologically the patients' sera for capsular reacting antibody or agglutinating antibody. Also we had not tested the serological relationship of our strains by the above-mentioned reactions. However, guinea-pigs inoculated with living cultures of the three strains were skin-tested for allergic reactions with heat-killed cultures of homologous and heterologous strains. The test was carried out as follows:-

One Dunklin-Hartley guinea-pig was inoculated subcutaneously with $0.5 \mathrm{ml}$. of a 24-hour glucose broth culture of each of the three isolates. Three weeks later the animal was inoculated intradermally into separate areas with heat-killed cultures $\left(60^{\circ} \mathrm{C}\right.$. for one hour) of the three strains. Similarly heatkilled cultures of $C$. neoformans innocuous and Candida albicans were injected into other areas as controls. Skin reactions appeared after two days not only on areas injected with the three strains of $C$. neoformans but also on those injected with $C$. neoformans innocuous and Candida albicans.

\section{DISCUSSION}

In all eight cases of cryptococcosis reported in China, there were symptoms of meningeal involvement before death and in seven of them C. neoformans had been isolated from the cerebrospinal fluid (Cheng, 1956). In our series, all three cases ended fatally after the development of meningeal symptoms. It appears that cryptococcal meningitis or meningoencephalitis is still the most frequent cause of death in this fungal infection. The course of the disease is variable.

C. neoformans is widely distributed in nature, for example, in milk (Carter and Young, 1950), in soil (Emmons, 1951), in various animals (Littman and Zimmerman, 1956), and in pigeon's nests (Kao and Schwarz, 1957). The organism is extremely resistant to dessication. According to Cheng (1956), dry powder of two strains of $C$. neoformans stored for one year and eight months was still alive upon transferring it to fresh cultural medium. He also found that dried sputum containing the organism gave growth upon inoculation to cultural medium a year afterwards. The high resistance to drying certainly has some significance in its epidemiology. Inhalation of dust from a contaminated source is the most probable mode of infection. However, there was no definite evidence to link the occupations of the patients reported here to these sources of infection. Emmons (see McCullough, Louria, Hilbish, Thomas, and Emmons, 1958) has pointed out that cryptococcosis was a non-contagious mycosis; that none of the other members of the big family of case 2 had the same complaint supports this point.
Clinically, cryptococcal meningitis and meningo- $\frac{\mathrm{\sigma}}{.}$ encephalitis are usually mistaken for tuberculous $\overrightarrow{\vec{F}}$ meningitis. This is especially true in the Far East, $\stackrel{\vec{P}}{+}$ where tuberculosis is still very common.

The presence of thickly encapsulated spherical, $\frac{\bar{\sigma}}{\bar{D}}$ budding, yeast-like cells in the sediment of the centri- $\frac{T}{2}$ fuged cerebrospinal fluid is suggestive of crypto- $\varrho$ coccosis. The capsule is best demonstrated by an कै Indian-ink preparation but a wet smear mounted in $\overrightarrow{0}$ lacto-phenol cotton blue is also useful, because it $\rightarrow$ digests the red blood cells and leucocytes leaving the $\vec{\omega}$ cryptococci and their capsules intact. The spherical shape of the fungus is an important criterion, for it? helps in the histological and cultural diagnosis of $\vec{\sigma}$ cryptococcus because most other yeast cells are egg- ir shaped or elliptical in outline. This point had been $\vec{D}$ emphasized by Emmons (see McCullough et al., $\vec{f}$ 1958).

It is not difficult to culture $C$. neoformans from $\vec{c}$ the cerebrospinal fluid, and Sabouraud's glucose $\mathbb{D}$ agar is the medium of choice. Duplicate sets incu- $\frac{\vec{D}}{\mathbb{D}}$ bated at $37^{\circ} \mathrm{C}$. and at room temperature might be set 3 up in case other fungi are looked for. As a rule, $C$. $\Phi$ neoformans grows much faster at $37^{\circ} \mathrm{C}$. than at room $\vec{\ominus}$ temperature on primary isolation. The differentiation $\stackrel{\circ}{\circ}$ of $C$. neoformans from the saprophytic cryptococci has been fully discussed by Benham (1956). In view of the irregularity of the results in the sugar fermentation test, the more reliable carbon assimilation test $\overline{0}$ should be used instead. Though the number of strains tested by us was small, our results were in full $\stackrel{\mathbb{Q}}{\Omega}$ agreement with those of Benham. All our strains $\overrightarrow{\overrightarrow{0}}$ hydrolysed urea in Stuart's medium within 24 hours. Seeliger (1956) found that this test was useful to screen the genus Cryptococcus from the ureasenegative Candida. It is, therefore, useful for primary identification of Cryptococcus isolated from mixed cultures. Nevertheless, animal inoculation is essential to discriminate $C$. neoformans from the saprophytic Cryptococcus species. The white mice, which are regularly susceptible to $C$. neoformans and succumb $\circ$ in a shorter period of time, are the animals of choice.

Actidione (Carton, 1952), nystatin (Brown and Hazen, 1957), and amphotericin B (Louria, Feder, and Emmons, 1957; Biddle and Koenig, 1958; $\sigma$ Fitzpatrick, Rubin, and Poser 1958; Seabury and N Dascomb, 1960) are all drugs which have been $N$ employed with some success in the treatment of cryptococcosis. Sensitivity tests of our strains in vitro showed that they were sensitive to these antifungal $\stackrel{0}{=}$ agents. In clinical practice, actidione and nystatin are $\stackrel{\mathscr{Q}}{\rightarrow}$ disappointing in the treatment of cryptococcal meningitis, because they do not reach appreciable levels in the cerebrospinal fluid and central nervous $\mathbb{D}$ system after intramuscular or intravenous injection $\frac{\Omega}{\mathbb{D}}$ (Littman and Zimmerman, 1956). In addition, 
nystatin is fairly toxic when administered parentally. Amphotericin B appears to provide promising results if it is used early. Treatment of cryptococcosis with amphotericin B has been observed to be successful by many workers. Only case 3 in our series was treated with amphotericin B, but no clinical improvement was achieved owing to the advanced stage of the disease. The failure of amphotericin treatment in systematic mycosis has been discussed fully by Utz and Andriole (1960).

We are grateful to Drs. H. L. Wen, Stephen Chang, and J. Hunter for the clinical notes of the patients whose cases are reported in this communication. We thank the U.S. Summit Corporation (Panama), local agent of E.R. Squibb and Sons, N.Y. for supplies of nystatin (Mycostatin) and amphotericin B (Fungizone); Dr. M. Silva, Department of Dermatology, College of Physicians and Surgeons, Columbia University, New York, U.S.A., for subcultures of $C$. neoformans innocuous.

\section{REFERENCES}

Benham, R. W. (1956). Bact. Rev., 20, 189.

Biddle, A., and Koenig, H. (1958). Arch. intern. Med., 102. 801.

Brown, R., and Hazen, E. L. (1957). Trans. N.Y. Acad. Sci., Ser. 2 , $19,447$.

Carter, H. S., and Young, J. L. (1950). J. Path. Bact., 62, 271.

Carton, C. A. (1952). Ann. intern. Med., 37, 123.

Cheng, W. F. (1956). Chin. med. J., 74, 374.

Fitzpatrick, M. J., Rubin, H., and Poser, C. M. (1958). Ann. intern. Med. 49, 249.

Emmons, C. W. (1951). J. Bact., 62, 685.

Kao, C. J., and Schwarz, J. (1957). Amer. J. clin. Path., 27, 652.

Littman, M. L., and Zimmerman, L. E. (1956). Cryptococcosis. Grune and Stratton, New York and London.

Lodder. J., and Kreger van Rij, N. J. W. (1952). The Yeasts a Taxonomic Study. Interscience Publishers, New York.

Loh Siew Whye (1951). Proc. Alumni Ass. King Edw. VII Med. Coll. $4,143$.

Louria, D. B., Feder, N., and Emmons, C. W. (1956-57). Antibiotics Ann. pp. 870-877.

McCullough, N. B., Louria, D. B., Hilbish, T. F., Thomas, L. B., and Emmons, C. (1958). Ann. intern. Med. 49, 642.

Pallis, C. (1949). Proc. Alumni Ass. King Edw. VII Med. Coll., $2,452$.

Russell, R. W. R., and Dean, D. (1957). Brit. med. J., 2, 627.

Seabury, J. H., and Dascomb, H. E. (1960). Ann. N.Y. Acad. Sci., $89,202$.

Seeliger, H. P. R. (1956). J. Bact., 72, 127.

Utz, J. P., and Andriole, V. T. (1960). Ann. N.Y. Acad. Sci., 89, 277.

\section{The July 1963 Issue}

\section{THE JULY 1963 ISSUE CONTAINS THE FOLLOWING PAPERS}

Inherited enzyme defects: a review T. HARGREAVES

A cytological and histological study of acute premyelocytic leukaemia JEAN BERNARD, J. LASNERET, J. CHOME, J. P. LEVY, and M. BOIRON

Cellular types in acute leukaemia: diagnosis and significance F. W. GUNZ and A. F. BURRY

Agglutination reactions of human leucocytes JEANETTE SCHULZ and HELGA MULLER

Fatal hepatic necrosis in glandular fever U. R. ALLEN and B. H. BASS

A study of the vesical ganglia in children and the relationship to the megaureter megacystis syndrome and Hirschsprung's disease SIDNEY LEIBOWITZ and MARTIN BODIAN

Four cases of Waldenström's macroglobulinaemia D'A KOK, D. N. WHITMORE, and R. W. AINSWORTH

Synergism between sulphonamide drugs and antibiotics of the polymyxin group against Proteus sp. in vitro F. E. RUSSELL

A new Pasteurella species (?) from a wound infection J. BRODIE and A. HENDERSON
A comparison of the measurement of gamma globulin in cerebrospinal fluid by electrophoretic and immunological methods JACK COLOVER, J. G. FEINBERG, ANNE TEMPLE, and MARIAN TOOLEY

Electrophoretic patterns of tumour tissue proteins EMIDIO AFONSO

A rapid micro method for recording red cell osmotic fragility by continuous decrease of salt concentration D. DANON

\section{Technical methods}

A new procedure for the identification of Pneumocystis carinii cysts in tissue sections and smears A. M. CHALVARDJIAN and L. A. GRAWE

Separation of myoglobin and haemoglobin on a column of dextran gel M. C. BERMAN and J. E. KENCH

A method for applying haemolysates on starch blocks for electrophoresis P. BARKHAN and M. E. STEVENSON

A routine method for staining eosinophils in sputum RICHARD W. PAYNE and R. H. HILL

The Association of Clinical Pathologists: 70th general meeting

International enzyme units and isoenzyme nomenclature Book reviews

Copies are still available and may be obtained from the PUBLISHING MANAGER, BRITISH MEDICAL ASSOCIATION, TAVISTOCK SQUARE, W.C.I, price 18s. 6D. 